the period of observation. Separate cases were observed seven years after the operation.

The operation consists of five steps described in the text and drawn in the attached Table.

The steadiness of the therapeutic results obtained, ease of the performance of the operation, the short duration of the postoperative treatment (5-6 days), all these data are, in the author's opinion, sufficient to recommend to oculists the application of the operation-antepositio conjunctivae fornicis-in severe forms of spring catarrh, not yielding to any other treatment.

\title{
A CASE OF ANGIOMA RETINAE
}

BY

DR. I. FEIG

haIFA, PALESTINE

Angroma retinae is an extremely rare anomaly or disease-it is in fact both of these simultaneously. Leber classifies the primary angioma and angiomatous degeneration of the retina together as Hippel-Czermak's disease of the retina, and gives a survey of 28 cases with which he was familiar. Czukrasz reports that during a period of 15 years at the Debrecen Hospital only two cases of angiogliosis retinae out of 100,000 cases of diseases of the eyes were encountered. Recently isolated cases of angiomatosis retinae, as well as several cases described as arterio-venous aneurysm, and one case of angioma of the choroid have been reported. Since, however, I have never found any case mentioned in literature available to me, similar to the angioma of the retina which was under my personal observation, I feel justified in recording the following case.

In June, 1937, Mrs. K.K., a specialist in children's diseases, came to consult me, and gave me the following history : 45 years of age, married, has no children (cause of childlessness known but of no significance as far as the disease of the eye is concerned), father died at the age of 67 years, of sepsis resulting from hypertrophy of the prostate, mother aged 74 years still in good health, five brothers and sisters, one of whom was killed in the Great War, the others in good health except for one stepbrother (descending from a different father) who has recently been suffering from diabetes. There have been no intermarriages in the family, nor have any diseases of the eyes been known of heretofore. Patient only had measles and mumps as a child. Married at age of 28 years, never gave birth, but had a doubtful abortion at one time. 
Immediately after acquiring her doctor's degree she fell ill with apicitis following an attack of Spanish 'flu (in 1918-1919) and hence remained for a year's time in Davos where she recovered completely. Since then she does not cough, or perspire at night, and has a good appetite. Three years later, in the north of France, she suffered from a bad attack of enteritis membranomucosa, which left her in a state of exhaustion. Three years ago she had what has been rather doubtfully described as varicose veins (phlebitis?) in the left leg; and two years ago, shortly after her arrival in Palestine, she had papataci with recidivation.

During an accidental examination of her eyes in her seventh term of study, she learnt of the anomaly in her right eye. The visual acuity as well as the visual field of both eyes was quite normal. From 1931 up to the date when her right eye became diseased, she wore spectacles for a slight hyperopia of this eye.

On January 10, 1936, en route to Europe from Palestine, she was suddenly stricken with an illness in her right eye, in Salonica her sight began to fail rapidly in this eye, gradually becoming dimmer, until very soon it went entirely blind, and according to the patient, even failed to react to light perception. The pupil did not react to light to any extent whatsoever, and the reflex of the pupil was missing altogether. In March of the current year (1937) the doctors in Salonica and in Zagreb could see nothing of the fundus of the eye.. In May, 1937, that is two months ago, the doctor in Zagreb could barely see a slight reflex from the pupil.

\section{General Condition}

Patient appears to be slightly neurasthenic and somewhat careworn; she is tall, of pale complexion, insufficient panniculus adiposus, and according to her own account (patient, as mentioned above, is a physician) the apices of her lungs are darkened. She does not cough, voice is not hoarse, heart has no pathological findings, pulse 70-80, blood-pressure low (104), has a small angeioma on the scalp, three small naevi on the skin of the abdomen, other organs without pathological findings.

\section{Ocular Condition}

Right eye.-In strabismus divergens position (according to patient, only since she began to suffer from this eye, i.e., over a year) patient prefers to wear a flap as the eye causes irritation since it has partly recovered its sight. In the lower eyelid, patient often feels fibrillar twitchings, especially when fatigued. Conjunctiva and cornea without pathological findings. Pupil of medium width and of equal size to that of the left eye, reacts 
to light and accommodation. Skiascopy +1.5 D.sph. visual acuity : sees movements of the hand in front of the eye, tension low Schiötz 9. Visual field cannot be measured; projection uncertain in supra-nasal direction, otherwise normal. Vitreous reveals thick flaked opacity. Picture appearing in ophthalmoscope (see illustration) is quite extraordinary-it may indeed be described as beautiful. In the region surrounding the papilla there is an outspread network of blood-vessels, in which upper and lower layers

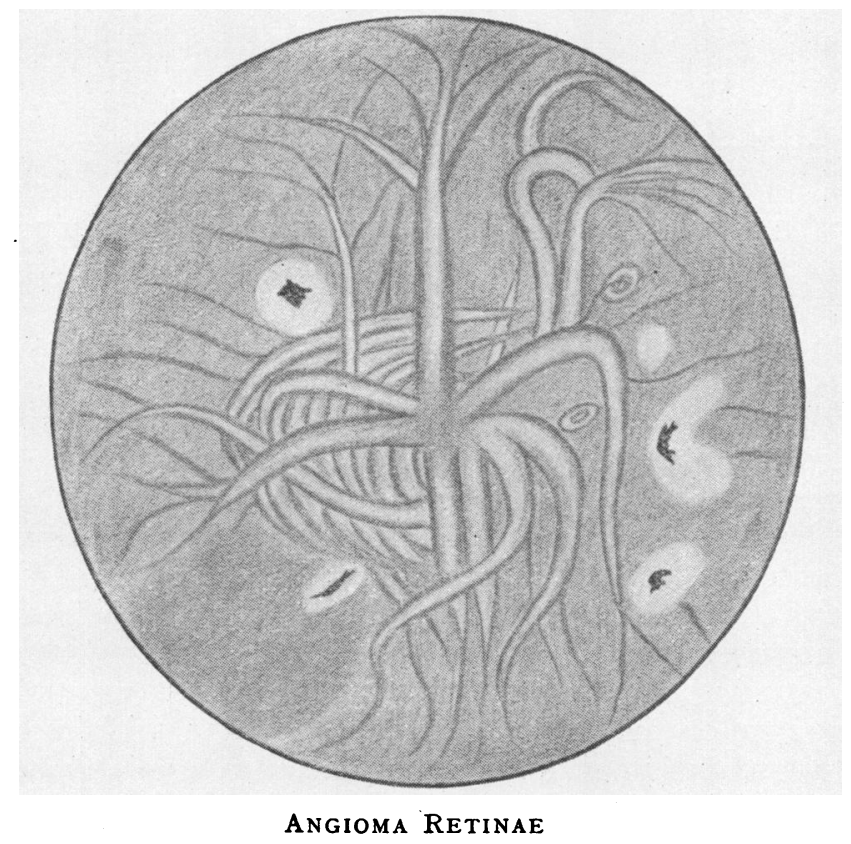

may be distinguished, partially entangled with each other. In the upper layer thick blood-vessels issue outwards in all directions (the thickest of these, which is almost of the thickness of the papilla, pointing downwards) and diminish spindle-wise in thickness after branching out, so that the retwork becomes thinner as it approaches the circumference. Below this, an entanglement of blood-vessels is visible, entwined among the upper ones, as mentioned above, and appearing like rings, in certain places. Within a range of approximately 6-7 times the width of the papilla, nothing but the blood-vessels can be seen. These are accompanied through their entire length by a white reflex, thereby making the fundus appear extraordinarily bright. At the circumference the retina is quite normally visible. Here, however, appear white areas of degeneration of the choroid, consisting 
of two larger areas, approximately the size of the papilla (one, however, a little larger than the other) both being encrusted with pigment, and a third area much smaller, without pigment at the temporal edge, besides two additional areas, one in the infra-nasal direction and the other in the supra-nasal direction, both of which contain pigment. Adjoining this last-mentioned area and towards the upper part of the circumference of the fundus is a region approximately four or five times the width of the papilla with a grey-greenish sheen, i.e., a partial surface detachment of the retina. Diaphano-scopical test with the Langé lamps produces a negative result.

Left eye.-The left eye is perfect in every respect, even the refraction being quite normal.

We have here, accordingly, an extremely rare case of apparently primary angioma which has not led to any other disturbances. The eye is far-sighted, $1.5 \mathrm{D}$.- a feature of the case which might perhaps be connected with the angioma. Up to the time of the disease, however, the sight of this eye was perfectly good and even the visual field was normal. Subsequently, however, haemorrhage into the vitreous occurred. It is doubtful whether this resulted from the papataci. It is, however, almost certainly connected with the anomaly of the eye, as in most of the cases that have been reported, as haemorrhage into the vitreous, as well as detachment of the retina occurs, although these were usually cases of angiomatosis retinae, whereas our case may be described as angioma retinae. It has been claimed that this disease may be related to tuberculosis. In this case, however, although the lungs reveal pathological findings, it would be most rash to connect the angioma or the detachment of the retina with the affection of the lungs. It is well known that haemorrhage into the vitreous on a tubercular basis occurs in the case of people who feel perfectly well, and whose lungs show no pathological findings, as well as in the case of young people below the age of 30 years. It is therefore more feasible to classify the haemorrhage into the vitreous and the detachment of the retina under the heading of angioma retinae although this may be left an open question.

It would be of interest to consider whether the naevi angiomatosi should also be included in this classification. Ludwig reports a case of angioma of the choroid accompanied by a red birth-mark, whereas Leber remarks that " no cases of complications with a telangiectasia or naevus vasculosus in another part of the body are known of," but this is not so in our case.

Implication of the brain, however, is indisputable. According to Lindau, in 20 per cent. of the cases of angiomatosis retinae, intracranial tumour occurs (these are usually cerebellar cysts) which are in reality angioplastic tumours and may be classified 
with the hyperplastic haemangioma group. It should be mentioned moreover, that Meller is of the opinon (contested, it is true) that in such cases there is an abundance of glia in the retina with a consequent degeneration which is followed by a development of the blood-vessels, and accordingly he calls this process gliosis retinae diffusa teleangiectodes. In a similar case, others refer to angiogliosis retinae. Hence the relationship to the cerebellar cysts may be recognised. Junius, however, refers to defective formation of the blood-vessels in one or more parts of the body. The origin of the anomaly is to be looked for in the third month of the foetus. Von Hippel believes that it is of ectodermal origin, whereas others hold the opinion that the origin is entodermal. Observations have been made of several cases in the same family, as well as of cases of both eyes being affected. Rochat believes that this disease is transmitted by the mother. According to Virchow, the angioma develops in all parts of the body from a telangiectasia which may escape attention at the time of birth and develop subsequently after 25,30 or 40 years into cavernous angioma. It is believed that the cavernous angiomata of the internal organs belong to this group whose development is thus deferred. This point of view explains the fact that the angioma of the retina as well as the implication of internal organs, especially the cerebrum, becomes manifest comparatively late in life. In addition to the Lindau cerebellar cysts, cerebral tumours and tumours of the spinal cord are referred to as complications of angioma retinae. Thus, Prevec declares that a certain case of angiomatosis retinae reported by him was associated with a pathological process in the spinal column which was diagnosed by surgeons as an intramedullar cystic tumour, and consequently he refers to " angiomatosis retinae et medullae spinalis."

In conclusion, the extreme rarity and the extraordinary aspect of this case should be emphasised. Leber writes that "the extension of the vessels does not usually commence to an equally great degree in the immediate vicinity of the papilla, but develops to its full height gradually at some distance from it, so that the blood-vessels are much broader before their entrance to the knot than at the papilla." Now in our case the posterior pole of the eye is entirely occupied by the angioma so that none of the papilla whatsoever is visible, whereas at the circumference the retina is more or less normally visible. In the Niccol and Moore case the angiomatous change is immediately adjoining the papilla but sharply defined, resembling a raspberry, of a reddish or purplish colour, tumour-like, projecting approximately $3 \mathrm{D}$. into the vitreous. The eye was removed. The cases reported as angiogliosis retinae are quite different. At this stage increase of tension is also reported, whereas in our case, the eye shows hypotension. 
As far as the brain is concerned, no objective changes are indicated. The "nervousness" which is definitely present, may be amply justified on psychical grounds (childless condition) and for other reasons as well.

After six months' observation no changes in the condition of the eye could be noted.

\title{
REFERENCES
}

1. LEBER.-Krankheiten der Netzhaut in Graefe-Saemisch-Hess Handbuch der gesamt. Augenheilk., Bd. VII, 1916.

2. Karasek.-Angiomatosis Retinae. Klin. Monatsbl. f. Augenheilk., Bd. XCV.

3. Prevec.-Ein Fall von angiomatosis retinae. Klin. Monatsbl. $f$. Augenheilk., Bd. XCVI.

4. Ludwig. Ueber Angiom der Aderhaut mit Feuermal der Schlaefengegend. Klin. Monatsbl.f. Augenheilk., Bd. XCV.

5. Niccol and MOORE - A case of angiomatosis retinae. Brit. Jl. of Ophthal., Vol. XVIII.

6. Junius.-Zur Frage der Angiomatosis Retinae. Ergebnisse und Folgerungen. Klin. Monatsbl. f. Augenherlk., Vol. XCI.

7. Rochat.-Familiaere Angiomatosis Retinae und Kleinhirn-angiom. Klin. Monatsbl. f. Augenheilk., Bd. LXXVIII.

8. CRUKRASz.-Angiogliosis retinae with report of two cases. Brit. Jl. of Ophthal., Vol. XXI.

\section{THE MICROSTRUCTURE OF EPITHELIAL CELLS AND ITS IMPORTANCE FOR THE AETIOLOGY OF TRACHOMA*}

\author{
BY \\ Professor Dr. Wilhelm Grüter \\ MARBURG
}

AN analysis of the different cell bodies, in particular of Prowaczek's bodies, presupposes thorough knowledge of all microstructures of the normal cell. Reliable judgment can be formed only from comparative study of the effect of organic and inorganic (chemical) reagents.

Analysis of the apparatus of Golgi occupies the front rank. There is considerable difference of opinion as to its existence in vivo. Some research workers consider it to be artificially produced, while others, e.g., Zeiger, claim that it is invisible in the dark field in vital examination.

\section{Material and Technique of Investigation}

Material.-Variola vaccine, herpes, diphtheria toxin, staphylococcic toxin, mustard oil, trachoma and conjunctivitis blennorrhoeica.

\footnotetext{
* Report read at the International Congress of Ouhthalmology, December 10 1937. Translation by the International Organisation against Trachoma.
} 